\title{
Lo Político en Jean Jacque Rousseau
}

\author{
Autor: Alirio José Abreu Suarez \\ Ministerio Del Poder Popular Para La Educación, MPPPE \\ alirioabreu2010@hotmail.com \\ Valera, Venezuela
}

\section{Resumen}

Este trabajo parte de una reflexión teórica sobre el pensamiento político de Jean Jacque Rousseau. El mismo fue efectuado con un enfoque bibliográfico y documental. En ese sentido, el trabajo propuesto se sustenta en las obras de Rousseau como: El origen de las desigualdades entre los hombres, el contrato Social entre otros autores. La obra roussoniana es importante ya que esta se convierte en un referente para el campo de las ciencias políticas. El propósito del texto es proporcionar a los docentes, estudiantes y demás actores elementos pedagógicos para que sean abordados y discutidos en el campo de las ciencias sociales. En la misma forma, es de destacar el aporte efectuado por Rousseau a la política, su visión sobre los sistemas de gobierno Democracia, Aristocracia y Monarquía fueron contundentes para la época ya que posteriormente políticos e ideólogos se inspiran en el para realizar la revolución francesa y el proceso de independencia en Latinoamérica. De igual forma, su dura crítica a la monarquía corrupta su afirmación de que la soberanía reside en el pueblo mediante voluntad general marca un antecedente interesante para las democracias actuales.

Palabras clave: democracia; estado; soberanía. 


\title{
The Political in Jean Jacque Rousseau
}

\begin{abstract}
This work is based on a theoretical reflection on the political thought of Jean Jacque Rousseau. It was carried out with a bibliographic and documentary approach. In this sense, the proposed work is based on the works of Rousseau as: The origin of inequalities among men, the Social contract among other authors. Roussonian work is important as it becomes a reference for the field of political science. The purpose of the text is to provide teachers, students and other actors with pedagogical elements to be addressed and discussed in the field of social sciences. In the same way, it is noteworthy the contribution made by Rousseau to politics, his views on the systems of government Democracy, Aristocracy and Monarchy were forceful for the time since later politicians and ideologists are inspired by it to realize the French Revolution and the process of independence in Latin America. Similarly, his harsh criticism of the monarchy corrupts his claim that sovereignty resides in the people through a general will and sets an interesting precedent for current democracies.
\end{abstract}

Keywords: democracy; state; sovereignty. 


\section{Introducción}

El pensamiento del político suizo - francés, Jean Jaque Rousseau (1712 - 1778), transciende gracias a sus aportes realizados en sus obras: El origen de las desigualdades entre los hombres, El contrato social, El Emilio, La nueva Eloísa, Confesiones entre otras. En ese sentido, fue un reformista en una sociedad inquisitoria. Es de precisar que para la fecha todavía imperaba la monarquía. La misma consideró de enemigo a todo al que realizara planteamientos políticos o educativos que pudieran colocar en peligro al sistema de gobierno de la época. En ese contexto Europa fue el centro de la producción literaria y Rousseau protagonista.

A ese periodo histórico también se le conoce como como el siglo de las luces o ilustración (XVIII), este se caracteriza por ser un movimiento intelectual y cultural europeo. Por lo tanto, existieron un gran número de filósofos, economistas, políticos e historiadores como: Denis Diderot, Jean Le D' Alembert, Adam Smith, Emmanuel Kant entre otros. Cada uno dio aportes importantes en el campo de la Filosofía, la política, la economía y Rousseau no fue la excepción.

De igual forma, Rousseau en el contrato social realiza severas críticas al poder político. Sus ideas políticas incomodan a la monarquía, a la aristocracia, a los nobles, terratenientes y demás instituciones de la época. Eso origina un odio y persecución al mismo viéndose este obligado a adoptar como nombre Renou. El ginebrino pasó momentos difíciles. Sus obras fueron quemadas de la mano de los verdugos. El infortunado Rousseau se veía arrojado de Francia, odiado en Berna detestado en Ginebra.

Rousseau transciende gracias a su magia y creatividad literaria. Su alto desempeño en el mundo de las letras tiene alto impacto en lo político y educativo. Sus planteamientos dieron origen a profundos cambios en lo político, el contrato social trajo como consecuencia la inspiración de líderes para hacer la revolución francesa en 1789. Después de ese hecho histórico 
comienza una nueva etapa en la vida de Europa. En otras palabras, comienza el final de la monarquía como sistema político.

Los planteamientos de Rousseau se inspiran en la justicia, la lealtad, el trabajo y demás valores que el ser humano pueda adquirir en la vida. Caracterizado también por ser un gran lector, escribiente y músico desde temprana edad fue amante de los clásicos griegos como la Republica de Platón y la política de Aristóteles entre otros. Además, seguidor de las ideas políticas de Voltaire, Locke, Descartes y Leibniz

Resumiendo lo tratado, Rousseau con sus obras promueve la democracia y funda el pensamiento crítico. Siguiendo a Vergara (2012a), señala: "Fundo una nueva tradición democrática la concepción participativa de la democracia, basada en el principio de la soberanía popular, la cual ha alcanzado un importante desarrollo en nuestro tiempo" (pág. 1). Parafraseando al autor, se desprende que el pensamiento político al igual que el educativo de Rousseau permanece como un referente para todos los actores sociales. Su aporte a la filosofía política lo hizo grande no solo por la capacidad de escribir temas relevantes y prohibidos. Su grandeza y principal virtud fue que no estuvo equivocado en sus planteamientos.

\section{Desarrollo}

En el desarrollo del tema, se tratarán aspectos fundamentales en la obra política de Rousseau como: Su visión sobre el tema de los derechos del hombre; el soberano y su papel dentro del Estado; el Estado desde la visión de roussoniana; su visión sobre la división de los gobiernos y la voluntad general como un derecho irrenunciable.

\subsection{Visión de Rousseau sobre los derechos del hombre}

Con relación a los derechos del hombre fue partidario de que existieran 
naciones en las que se respetara la convivencia social y el respeto. Así como también que predominara la justicia. En ese sentido, Rousseau en su obra El Origen de las Desigualdades entre los Hombres (2006a), indica: "Yo habría escogido un país en donde el derecho de legislación fuese común a todos los ciudadanos, por qué, ¿quién puede saber mejor que ellos, en qué condiciones les conviene vivir reunidos en una misma sociedad?" (pág. 10). Interpretando al autor, se puede decir que los habitantes de una sociedad están en su derecho de implementar o contribuir en el desarrollo político, económico y social de la nación.

Respecto a lo anteriormente expuesto, Abreu (2017), dice: "Existe una serie de derechos que no deben ser violados" (pág. 340). Al respecto, los derechos políticos son parte de la vida del hombre. Rousseau fue contrario al sistema imperante. Condenó la esclavitud o la servidumbre en todas sus esferas ya que en palabras de Rousseau (2006b), señala: "Ios pueblos una vez acostumbrados a tener amos o señores no pueden después vivir sin ellos" (pág. 9). Sumado a lo expuesto, el hombre por naturaleza es un ser que en su subconsciente es gobernado por políticos buenos, malos, eficientes 0 deficientes. A la vez, se convierte esclavo de sus opresores mediante el pago de impuestos, servicios ineficientes, contribuciones especiales, entre otras.

Rousseau, consideró a la sociedad como un gran pacto en donde existe una asociación que proteja y defienda a toda la comunidad. Así como también a las personas y sus bienes. Todo eso bajo el principio de la libertad común, ya que el pueblo es un conjunto de personas asociadas con un fin y el gobierno tiene la tarea de salvaguardar la voluntad popular. En referencia a la libertad la ve como un derecho irrenunciable. Rousseau en su Contrato Social (1959a), indica: "Renunciar a su libertad es renunciar a su condición de hombre, a los de la humanidad y aun a sus deberes. No hay resarcimiento alguno para quien renuncia todo" (pág. 848). En otras palabras, el hombre debe de luchar por tener libertades, derechos políticos, sociales y económicos. 
Resulta claro que las ideas de Rousseau en su contrato social fueron apropiadas por los importantes políticos de la Europa moderna. La esclavitud, opresión, degradación del ser humano y la falta de derechos fundamentales del hombre comienzan a difundirse y debatirse para dar paso a un sistema parlamentario que plasmaría en las constituciones venideras los deberes derechos y garantías de las personas.

Por su parte, Rousseau fue amante de la libertad y la justicia social condenó la opresión, los crímenes, la pobreza en que vivía la mayoría, mientras la comodidad y la opulencia era una característica de los reyes. En torno a eso Rousseau (1959b), expresa: "el hombre ha nacido libre y, sin embargo, vive encadenado en todas partes entre cadenas" (pág. 843). Al respecto, el músico, maestro y actor ginebrino fue un férreo amante de la libertad sin que esta sobrepasara los derechos y deberes ciudadanos.

Por su parte, Rousseau fue defensor del derecho a la vida parte del principio de que no hay derecho alguno para quitar la existencia de personas que hayan sido sometidas en combate. Consideraba que era preferible convertirlo en esclavo mientras este se libera. Por otro lado, ese planteamiento fue acogido en la revolución francesa en la proclama sobre el primer derecho fundamental del hombre, ese derecho es el de la vida. En igual forma, el autor del Emilio fue amante del estado natural del ser humano y como tal amaba la paz siguiendo a Fukuyama (1992), indica:

Rousseau postula un estado de naturaleza pacífico. Niega que la vanidad o el amor propio sea natural en el hombre, y sostiene que el hombre natural temeroso y solitario, es esencialmente pacifico, porque sus pocas necesidades egoístas se satisfacen fácilmente (pág. 345).

Como complemento, es de destacar que la paz era para Rousseau un anhelo permanente por tratarse parte de la naturaleza humana, el hombre nace libre y no tiene por qué vivir encadenado. El político no nace corrompido, 
es el sistema imperante lo que lo hace corrupto, ineficiente, indolente a los problemas de la sociedad y sobre todo a los más desposeídos. Asimismo, critica en sus obras el Emilio y el Contrato Social a todo ese aparato gubernamental que no daba felicidad a la mayoría sino opresión.

Frente a este escenario, defendió los pactos sociales como una manera existencial de los seres humanos. Por lo tanto, en la sociedad deben existir pactos políticos, económicos, sociales en donde la libertad sea un referente. También consideró las relaciones diplomáticas como parte esencial de un país. Al respecto, Rousseau (1959c), Manifiesta:

Encontrar una forma de asociación que defienda y proteja con la fuerza común la persona y los bienes de cada asociado, y por la cual cada uno, uniéndose a todos, no obedezca sino así mismo y permanezca tan libre como antes (pág. 853).

Interpretando al autor, la organización en todos los ámbitos expuestos es un derecho y obligación de la sociedad. Del mismo modo, plantea que solo en libertad el hombre puede vivir justamente, aunque con algunas dificultades por el estado natural del hombre. Por esta razón, es que el planteamiento libertario del ginebrino estuvo ligado a la naturaleza propia del hombre.

\subsection{El soberano y su papel dentro del Estado desde la perspectiva de Rousseau.}

Para Rousseau los pactos sociales son fundamentales en cualquier sociedad. Estos evitan el estado de la barbarie o primitivo, que no es otro que la fuerza por encima de la ley. En ese orden, consideró la participación del soberano en la construcción de normativas con el fin establecer derechos y deberes comunes. Al respecto, Rousseau (1959d), expresa: "Las leyes no son propiamente sino de las condiciones de la asociación civil. El pueblo sumiso a las leyes, debe ser su autor; corresponde únicamente a las que se asocian a regular las condiciones de la sociedad" (pág. 875). Como complemento, el 
ciudadano está en la obligación de participar en la elaboración y construcción de leyes de manera directa e indirecta una de ellas es haciéndole planteamientos a los legisladores.

Sumado a lo expuesto, Rousseau (1959e), indica: "Puesto que las leyes emanan de la voluntad general, ni el príncipe está por encima de ellas, toda vez que es miembro del estado" (pág. 874). Es decir, las leyes tienen el propósito de establecer el orden social. En ese sentido, las monarquías el alto clero, las cúpulas militares, políticas o económicas no pueden estar exceptas de cumplir con lo que establece la ley.

De acuerdo con el autor, consideró al soberano como un cuerpo capaz de generar propuestas para transformar el estado monárquico en un Estado social más justo. Visto de esa forma Zarka (2005a), manifiesta: "El pensamiento de Rousseau constituye un giro en la medida misma en la que funda un nuevo concepto de soberanía del pueblo que va a ocupar el centro de la reflexión política hasta nuestros días" (pág. 2). Dicho de otro modo, las ideas de Rousseau fueron de gran impacto en las revoluciones de los siglos XVIII, XIX, XX.

Asimismo, Rousseau planteaba que el poder del soberano es inalienable e indivisible. Por lo tanto, no se puede negociar con el pueblo asuntos que vayan en su contra como los aspectos siguientes: el derecho de ser libre, expresar sus ideas políticas, religiosas y de decidir en todo lo que tiene que ver con el destino de la sociedad. Criticó a los políticos de la época por considerar al soberano un cuerpo sin principios y sin formación para generar ideas, debates y propuestas. De igual forma, planteaba que la fuerza y la voluntad estaban expresadas en los poderes legislativos y ejecutivo respectivamente. Lo que se traducía en impuesto y guerra algo que atentaba contra el soberano.

De igual forma, consideró que el soberano es un cuerpo recto en su proceder ya que generalmente quiere el bien común. Siguiendo el 
planteamiento Rousseau (1959f), expresa: "El pueblo jamás se corrompe, pero a menudo se le engaña, y es entonces cuando parece querer el mal". (pág. 866). De acuerdo con el autor, el soberano también tiene debilidades ya que por su naturaleza de hombre ve frustradas sus aspiraciones por políticos inescrupulosos lo que lo conllevan a tomar acciones como la rebeldía y desobediencia. También cabe destacar que el soberano se frustra cuando el pacto social se rompe.

\subsection{El Estado desde la visión de Rousseau}

Con respeto al Estado, Rousseau lo definió como una persona que tiene que tener moral y que hace vida con sus semejantes. Esto conlleva a la unión de sus miembros. En la conformación del Estado participan varios factores sociales, en él debe existir un pacto social que regularice la convivencia entre los ciudadanos. De ese modo, lo conforman los individuos y los mismos se nutren de la tierra.

Cabe destacar, que Rousseau plantea un Estado que sea gobernable y para cumplir ese objetivo este no debe ser ni muy grande o muy pequeño. En este sentido, el primero de estos exige muchos recursos económicos y también un elevado número de hombres al servicio del Estado para poder contener las revueltas o rebeliones. También es indispensable contratar mano de obra con salarios elevados para los asuntos de gobierno. En consecuencia, un Estado gigante en extensiones territoriales se mantiene solo con el recargo de los impuestos al pueblo lo que genera decadencia en su calidad de vida.

Por el contrario, un Estado pequeño es difícil de sostenerse por los pocos recursos económicos o humanos que este tenga, pero a la vez tiene la ventaja que la población tiene muchas cosas en común lo que hace que exista un sentido de pertenencia y amor por la nación. Sumado a lo expuesto, Rousseau (1959g), dice:

Mil razones demuestran que este principio. Primeramente, la 
administración se hace más difícil cuanto mayores son las distancias, al igual que un peso es mayor colocado en el extremo de una gran palanca. Hácese aún más onerosa a medida que los grados se multiplican, pues cada ciudad como cada distrito tiene la suya, que el pueblo paga; luego los grandes gobiernos, las satrapías, los virreinatos, que es preciso pagar más caro a medida que se asciende, y siempre a expensas del desdichado pueblo; y por último la administración suprema que lo consume todo (pág. 882).

De acuerdo con lo antes citado, el impuesto que se cobra al soberano no se traduce en mejorar los servicios o vida de los contribuyentes. Según el autor, existe un aparato burocrático que consume todo lo contribuido por el ciudadano. Así como también, un desperdicio de recursos económicos en extravagancias, lujos, seguridad entre otros aspectos. De acuerdo con lo planteado Rousseau justificaba un Estado que se pudiera mantener sin necesidad de que recayera en el soberano el peso de su mantenimiento. Igualmente, consideró que el gobierno es un cuerpo intermedio que lo establecen los súbditos el soberano y los súbditos encargados de que se cumplan las leyes y la libertad civil y política.

En el mismo orden de ideas, para Rousseau el gobierno lo conforman los magistrados también conocidos como reyes o poder ejecutivo. El mismo Consideraba que para que un gobierno sea bueno primero tiene que ser fuerte a medida del crecimiento de la población. A la vez, planteaba que el pueblo y gobierno deben contener sus acciones mutuamente.

Del mismo modo, el gobierno debe distinguirse de los demás poderes del Estado por ser el administrador director de los recursos económicos. Es decir, el Estado siempre existirá por si solo y el gobierno se debe al soberano quien es él que lo ubica en esa función para que cumpla funciones transitorias en el poder político por y para la sociedad. Todos los miembros de un gobierno deben obrar y responder de acuerdo con las funciones para lo que ha sido colocado. 
Para Rousseau el gobierno debe de gozar de buena salud o credibilidad dentro del pueblo eso le hace más fácil la gobernabilidad. Los gobernantes son prestados por un tiempo específico ya que cuando un gobierno dura mucho tiende a corromperse y a usar técnicas y estrategias inescrupulosas para seguir ostentando el poder. En ese sentido, el soberano se convierte en un contralor de las políticas usadas por los hombres en función de gobierno. Existen dos planteamientos relacionados de lo que es gobierno según Rousseau: El primero relacionado con el ejercicio de la voluntad popular o del soberano lo que traduce a gobierno legítimo y la segunda de que la suprema administración se debe solo a un mandato del soberano.

\subsection{Rousseau y su visión sobre la división de los gobiernos.}

Rousseau condena el poder político en manos de un solo hombre. Al respecto, Rousseau (1959h), señala: "cuando el gobierno se encuentra en manos de un solo hombre, la fusión de la voluntad popular y la general es perfecta, y por consiguiente esta alcanza mayor grado de intensidad posible" (pág. 897). Es decir, cuando una sola persona se afianza en la función de gobierno se da cabida a luchas o rebeliones de los ciudadanos ya que estos solo quieren un bien común que es el de la participación social en los asuntos referentes a su nación.

Por su parte, Rousseau como estudioso de las ciencias políticas e inspirado en las ideas de Sócrates, Platón, Aristóteles, Montesquieu, Voltaire, entre otros, realiza un análisis histórico de los gobiernos que han existido a lo largo de la historia. Todo esto lo lleva efectuar una clasificación de la división de los gobiernos de la siguiente forma: Democracia, aristocracia y monarquía.

En primer lugar, la democracia es para Rousseau la participación del pueblo en cuanto a la elección directa de sus representantes en el gobierno o lo que es lo mismo su libre autodeterminación en los asuntos de su país. En el 
Estado democrático la mayoría tiene el derecho de decidir los destinos del país a través del voto. Para Vergara (2012b), "El Estado democrático rusoniano es el pueblo convertido en sujeto colectivo que se autogobierna. El acto de asociación le otorga su unidad, su yo común, su vida y su voluntad" (pág. 1). En otras palabras, la voluntad popular es irreversible e inalienable. Rousseau (1959i), indica: "Si hubiera un pueblo de dioses, se gobernaría democráticamente. Un gobierno tan perfecto no conviene a los hombres" (pág. 902). Es decir, la democracia es el sistema adecuado ya que es el que permite la participación social con todas y las debilidades que se puedan atribuir.

En segundo lugar, la aristocracia según el ginebrino es un sistema de gobierno en que el poder del mismo se encuentra en pocas manos por lo que esto puede llevar a la tiranía y corrupción. En este sentido, ese sistema es bastante antiguo y las primeras sociedades se gobernaron aristocráticamente participando en el mismo el consejo de ancianos, patriarcas, senado entre otros.

Rousseau (1959j), manifiesta: "Esta forma de gobierno tiene dos personas morales muy distintas; el gobierno y el soberano y, por consiguiente, dos voluntades generales, una con relación a todos los ciudadanos, la otra, con relación a los miembros de la administración solamente" (pág. 902). Parafraseando al autor, la aristocracia es un pequeño grupo que rige el destino de muchos. En él interactúan las voluntades del minúsculo y diminuto número de personas que gobierna, hacen las leyes, son jueces, jefes militares, administradores de la hacienda pública, entre otros.

En tercer lugar, la monarquía es el poder de gobernar en una sola persona a lo que Rousseau denomino también magistrado y los demás hombres reciben su voluntad única, también denominada gobierno real. En cuanto a ese sistema existen debilidades ya que históricamente han realizado pactos de gobernabilidad. Rousseau (1959k), dice: "la monarquía también es susceptible de alguna participación" (pág. 899). Ante lo señalado, es de 
precisar que cuando las extensiones de una nación son demasiadas extensas pueden traer consecuencias negativas de gobernabilidad. En torno a esto, se hacen necesarios algunos acuerdos que garanticen su permanencia.

Con relación al planteamiento anterior, es obvio que Rousseau fue un serio crítico del sistema de gobierno monárquico por considerar que estaba basado en la concentración del poder político en un hombre y, por lo tanto, no representaba al soberano ni a la voluntad popular. De igual forma, no vio con buenos ojos que el monarca dispusiera de la justicia a su antojo y que una gran masa poblacional fuera gobernada por la mano de una individualidad.

En ese sentido, esos postulados trajeron graves consecuencias para el autor del contrato social el cual pasó gran parte de su vida en el anonimato. Asimismo, Rousseau (1959l), señala: "Los reyes desean ser absolutos, y desde lejos se les grita que el mejor medio para hacerlo es hacerse amar de sus pueblos" (pág. 905). Es decir, considero que a los monarcas se les adula y los mismos aparentan amar al pueblo, pero desgraciadamente se burlarán siempre de ellas en las cortes.

De la idea planteada, se corrobora el gran espíritu de demócrata y valentía de Rousseau. El mismo condenó las luchas internas desde el seno de las monarquías para ostentar el poder político ya que no se consideraban merecedores de gobernar. La ausencia de un monarca que por motivos de salud, fallecimiento e incapacidad para ser príncipe no debe dar cabida para que el trono sea hereditario, sino por el contrario tiene que ser el pueblo que mediante elección libre elija su sucesor. A la vez, planteo que cualquiera que esté ligado a la monarquía no puede ser rey ya que esto exige: trabajo, compromiso, sabiduría y paciencia entre otros aspectos. Elementos estos de lo que carecían un gran número de monarcas a lo largo de historia. 


\subsection{La voluntad general como un derecho irrenunciable desde la perspectiva de Rousseau}

En el periodo de la ilustración o siglo XVIII, también conocido como el siglo de las luces existieron voces en contra de las monarquías como sistema imperante en la Europa. Este es el inicio de la decadencia de los reyes de la edad moderna. Una de esas voces que se pronunció con más fuerza fue sin duda la de Rousseau. El mismo afirmó que en las sociedades el pueblo debe jugar un papel preponderante en cuanto a la elección de su gobernante y aprobar y desaprobar leyes, eso lo han de realizar por el bien común así lo planteó el autor del Emilio. En ese sentido, el voto es una vía para tal fin.

Cabe señalar, que todo lo relativo a los eventos que puedan influir en la vida de las personas tienen que ser consultados a la población. Rousseau fue partidario de tomar en consideración para la ejecución de normativas 0 instrumentos de tipo jurídico a la voz de pueblo. Un mecanismo para eso es el voto de manera libre y voluntaria, a la vez, planteaba que la expresión popular ha de considerase y respetarse sin colocar objeciones a la misma. Asimismo, Rousseau (1959m), indica: "el simple derecho de votar en todo acto de soberanía, derecho que nadie puede arrebatar a los ciudadanos, y sobre el de opinar, proponer, dividir y discutir" (pág. 935). Siguiendo la idea del autor, el voto es la vía para expresar los acuerdos desacuerdos con los gobernantes.

De igual forma, Rousseau sostuvo que la indestructibilidad de las mayorías es un hecho ya que el pueblo es quien debe manifestarse en lo referente al nombramiento de los príncipes, reyes, legisladores entre otros. De acuerdo con Zarka (2005b), dice: "Con Rousseau la soberanía del pueblo proporciona el único concepto legítimo y válido de la soberanía, como puede mostrarse tanto en relación con los términos del contrato social, como con el concepto de voluntad general" (pág. 8). Parafraseando al autor, se puede mencionar que el poder político adquiere una profundad legitimidad cuando existe la participación del soberano en cuanto a la elección del gobierno. 
Asimismo, y referente a la voluntad popular Vergara (2012c), Expresa: "El Estado democrático rusoniano es el pueblo convertido en sujeto colectivo que se autogobierna" (pág. 1). Interpretando lo planteado, la voluntad popular es una realidad de las democracias en estos sistemas es donde existe la participación y manifestación de las mayorías que colocan a una minoría para dirigir los asuntos de gobierno.

De igual manera, el autor de la Nueva Eloísa consideró los actos de elegir a los gobernantes como un hecho difícil, aunque parezca sencillo. El pueblo tiende a equivocarse y por tal motivo no elige al más adecuado. Planteaba que los monarcas y representantes de las cámaras tienen que ser electos por voluntad popular. A la vez, deben utilizar una metodología que esté acorde con la realidad del país ya que las naciones son de diferentes contextos políticos, sociales, culturales y económicos. Reafirmando el planteamiento anterior. Smith (2008), indica.

Rousseau sostiene también su tesis de la infalibilidad de la voluntad general desde la teoría organicista con la cual intenta demostrar que el buen funcionamiento de un Estado depende, como un cuerpo, de que sea dirigido por una sola voluntad, o sea, por la voluntad misma del pueblo soberano como cabeza del cuerpo político que forma y que, como tal, nunca pueda tener otro interés que no sea el del cuerpo mismo (pág. 38).

Con relación a lo expuesto, las ideas políticas de Rousseau fueron la reafirmación de un Estado que tenga como fin la felicidad de las mayorías en donde se respeten las leyes, personas, vida, voluntad popular, propiedad, actos o pactos sociales entre otros. Es el pueblo quien determina mediante el voto como instrumento para designar quien va a ocupar una función de carácter permanente o transitoria de los destinos de la administración púbica. En ese sentido, el pensamiento político del ginebrino consiste en darle al soberano participación para que sea dueño de su propio destino a través de elecciones populares en donde estén incluidos todos los sectores sin 
excepción alguna.

\section{Reflexión final}

La obra política de Jean-Jacques Rousseau, históricamente fue sin duda una de las más trascendentales durante el periodo de la ilustración. Actualmente Rousseau es considerado uno de los padres de la democracia que hoy el mundo conoce, su texto El contrato social es el instrumento que fue estudiado por otros notables políticos y líderes de la revolución francesa como: Maximilian Robesspiere, Jean-Paul Marat, George Danton, entre otros.

Del mismo modo, la propuesta de Rousseau, sobre los derechos humanos como: la vida, el voto, soberanía, democracia y libertad entre son aspectos aún son debatidos en el mundo de las ciencias políticas y la filosofía política. Aunque esos planteamientos no fueron nuevos a él se le otorga el mayor crédito por generarse transformaciones de orden político en la Europa contemporánea.

De igual forma, el modelo teórico rousoniano planteado en El Contrato Social, da una explicación racional de las relaciones humanas. En donde el hombre tiene una relación con el Estado mediante asociaciones políticas. Por lo tanto, para Rousseau había que socializar a las personas de la edad moderna y los posteriores contextos cronológicos.

En el mismo orden de ideas, Rousseau partió del principio de que para vivir en una sociedad más justa el ser humano tiene que vivir el estado natural. En otras palabras, no corromperse ni ser un individualista ya que el hombre es bueno por naturaleza y la sociedad es la que lo corrompe. Planteaba que el hombre es perfectible a medida que toma conciencia de lo que le conviene o no a una nación.

Asimismo, el partir de una moral de la voluntad general idea que introduce Rousseau al campo político es un referente para las sociedades contemporáneas. En el mundo rousoniano la complementariedad entre 
hombre y sociedad es una relación necesaria ya que ninguno puede aislarse del contexto en que está inmerso. Sin embargo, Rousseau no fue comprendido por muchos, fue atacado, perseguido, calumniado y expulsado de algunos países injustamente por las cúpulas políticas y eclesiásticas. Sus pensamientos e ideas tal vez fueron muy avanzadas por lo que no fueron aceptadas para la época. Sus obras: El contrato social, El origen de las desigualdades entre los hombres, El Emilio, La nueva Eloísa entre otras, hacen del mismo un gran analista en el campo de las ciencias políticas.

Hoy las ideas políticas de Jean Jacques Rousseau, son estudiadas en diversas universidades del mundo. Su aporte a la política es significante ya que existieron desenlaces concretos que se inspiraron en su obra como: la revolución francesa y los procesos de independencia de Latinoamérica y el Caribe. Muchos pueden estar de acuerdo o desacuerdo con su pensamiento, pero lo que si es cierto es que el aporte de Rousseau fue fundamental en transformación política e ideológica de un considerable número de países. Por lo tanto, la humanidad le debe a este pensador el ser el padre de las democracias modernas.

\section{Referencias}

Abreu, A. (2017). La Ética en la Investigación Educativa. Revista Scientific, 2(4), 335-350. Recuperado de:

https://doi.org/10.29394/scientific.issn.2542-2987.2017.2.4.19.338-350

Fukuyama F. (1992). El fin de la Historia y el último hombre. Colombia: Editorial Planeta.

Rousseau J. (1959a,b,c,d,e,f,g,h,i,j,k,l,m). Obras selectas de Juan Jacobo

Rousseau. Argentina: Editorial Ateneo.

Rousseau, J. (2006a,b). El origen de las desigualdades entre los hombres. Bogotá: Ediciones Universales.

Smith A. (2008). Estado y Democracia en el Pensamiento Político de Jean- 
Jacques Rousseau. Santo Domingo, República Dominicana: Instituto filosófico Pedro Francisco Boná. Recuperado de:

https://www.memoireonline.com/02/12/5369/m Estado-y-democraciaen-el-pensamiento-politico-de-Jean-Jacques-Rousseau4.html Vergara J. (2012a,b,c). Democracia y participación en Jean-Jacques Rousseau. Revista de Filosofía. Volumen 68, págs. 29-52. Recuperado de:

http://www.scielo.cl/scielo.php?script=sci arttext\&pid=S071843602012000100004

Zarka, C. (2005a,b). Rousseau y la soberanía del pueblo. Revista Derechos y Libertades, Número 15, Época II, págs. 47-63. Recuperado de: https://www.dykinson.com/cart/download/articulos/3281/ 


\section{Alirio José Abreu Suarez \\ e-mail: alirioabreu2010@hotmail.com}

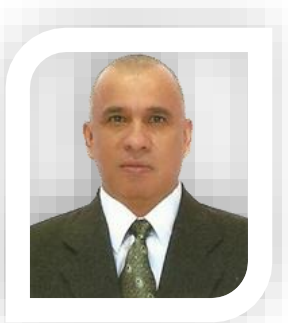

Nacido el 03 de diciembre de 1966 en Valera, estado

Trujillo, Venezuela. Licenciado en educación integral mención ciencias sociales en la Universidad Nacional Experimental Simón Rodríguez. Especialista en planificación y evaluación educativa Universidad Valle del Momboy. Especialista en educación para la recreación comunitaria egresado de la Universidad de Pamplona (Colombia). Experiencia Universitaria: docente de la Universidad Deportiva del Sur, docente en la Universidad Politécnica de las Fuerzas Armadas. Actualmente profesor activo en el Ministerio del Poder Popular para la Educación, clasificación V. Lugar de trabajo Escuela Primaria Bolivariana Caja de Agua adscrita al NER175, ubicada en Motatán, Estado Trujillo, Venezuela y Doctor en educación en la Universidad Nacional Experimental "Rafael María Baralt". 